\title{
OS VERSOS DE EUSTACHE DESCHAMPS COMO FONTE PARA A HISTÓRIA CULTURAL DA FRANÇA NA BAIXA IDADE MÉDIA
}

Carmen Lucia Druciak ${ }^{1}$

Nature en suis forsenée, Acourée,

Tourmentée, Chetive et descoulourée.

C'estoit le meillour,

En amour,

En douçour

Sanz cremour,

En puissance et en vigour.

Qui peust venir en armée.

E. Deschamps, Lai IX

\section{Introdução}

O estudo da produção poética da Baixa Idade Média oferece condições de enriquecer $e$ ampliar o que se sabe sobre a cultura $e$ a vida em sociedade desse período, sobretudo no que se refere ao entorno das monarquias vigentes, conjunto de matérias de grande interesse para a História Cultural da França na Baixa Idade Média.

A produção escrita profana ${ }^{2}$ do período tardo-medieval já havia conhecido os romances de cavalaria, as canções de gesta e igualmente a poesia dos trovadores occitanos do sul da França em que a expressão do eu lírico havia aberto caminho para uma poesia em língua francesa cuja subjetividade, enquanto realidade emocional e psíquica, bebia do frescor das novidades do dia-a-dia, nutrindo-se daquilo que era novo e de que "[era] agradável e prazeroso ocupar-se"3. Daí, perceber a consciência de si nessa produção é quase que natural ao analisarmos as transformações que o "ofício" de poeta experimentava na França nos fins da Idade Média. Vale salientar igualmente, que os autores de obras líricas alimentavam sua

\footnotetext{
${ }^{1}$ Doutoranda do programa de Pós-Graduação em História da Universidade Federal do Paraná em cotutela com a Universidade de Poitiers, na França. Bolsista CAPES. <carmem.druciak@gmail.com>.

${ }^{2}$ Evidentemente, ao falar sobre expressões literárias do medievo e mesmo do período tardo-medieval, não podemos entender o termo literatura tal como o conceito difundido a partir de fins do século XVIII $e$ ao longo do XIX e vigente nos dias de hoje, já que o uso estético da linguagem ainda não havia sido considerado em sua totalidade como arte autônoma. Apesar disso, os homens e mulheres de letras desse período mostravam consciência dos diferentes registros com que escreviam em língua vulgar: crônicas, poemas, tratados políticos, etc. Ver, por exemplo, a obra de Jean Froissart, Christine de Pizan, Pero Lopez de Ayala, para citar apenas alguns.

${ }^{3}$ ZINK, Michel. Froissart e o tempo. Curitiba: Editora UFPR, 2016, p. 90.
} 
produção com sua experiência pessoal, pois "a expressão poética é uma expressão de identidade [...]. A poesia oferecerá expectativas, sínteses, revelar-se-á nas relações, nas metáforas" 4 .

Além disso, compreender a prática desses autores e percebê-los como homens de saber $^{5}$, possibilita situar as diferentes expressões escritas que foram ganhando contornos mais visíveis nesse período, como por exemplo, a escrita que se encarregava do interesse pela História vindo da parte dos reis e dos reinos, enquanto produto de letrados que "podiam desfrutar de certa liberdade intelectual e reivindicar uma real autonomia para o grupo social que eles próprios constituíam"6.

Acreditamos que todo documento ao ser analisado pelo historiador se torna uma fonte histórica. É indispensável, portanto, quando o historiador medievalista convoca entre suas fontes textos literários, que ele o faça buscando compreender quais foram as escolhas do autor daquele texto $e$ a imagem que ele quis dar de si mesmo, acrescentaríamos a isso, a questão sobre seu destinatário e sobre os usos que seus contemporâneos fizeram daquela obra, entre tantas outras indagações. Aliás, é a pergunta do historiador ao documento e sua abordagem que conferem a ele seu caráter de fonte. Cabe ao historiador fazer à sua fonte textual "perguntas fundamentais", como orienta o pesquisador José D'Assunção Barros ${ }^{7}$, sem deixar de considerar suas dimensões contextuais, intertextuais $e$ intratextuais, continua $o$ pesquisador. Além disso, objetivando não separar o conteúdo da testemunha, o historiador deve "interrogar todas as fontes, por mais diversas que elas se apresentem, por mais difíceis que sejam, tal é o engajamento primeiro a que o historiador está ligado, a fim de se colocar em posição de apreender os problemas em toda sua complexidade". ${ }^{8}$

Ao longo destas páginas, vamos nos debruçar sobre uma pequena parte da produção escrita do período tardo medieval na França: uma amostra da obra de

${ }^{4}$ GUIMARÃES, Marcella L. "Sintomas de renovação na poética tardo-medieval", p. 20; 22 (inédito).

${ }^{5}$ A expressão foi conceituada por Jacques Verger ainda nos anos oitenta e noventa do século XX em sua obra Les Gens de Savoir dans l'Europe de la fin du Moyen Âge, traduzida para o português em 1999. Em artigo publicado em 2014, o professor Igor Salomão Teixeira, da UFRGS, discute justamente a designação desses homens que trabalhavam com a palavra no fim da Idade Média, servindo-se das discussões dirigidas por Jacques Le Goff, Jacques Verger e outros autores, a fim de reanimar as discussões sobre esses intelectuais ou homens de saber. Vale salientar, no entanto, que o professor Teixeira não inclui em suas explanações as produções consideradas líricas. Entendemos, pois que, das artes liberais que ocupavam os trabalhos nas universidades $e$ as atividades de clérigos, restritos à Igreja ou à nobreza, o ensino do que hoje entendemos por poesia, não era contemplado naquele contexto. Cf. TEIXEIRA, Igor. S. "O intelectual na Idade Média: divergências historiográficas e proposta de análise", Revista Diálogos Mediterrânicos $\mathrm{n}^{\circ}$ 7, dez/2014, p. 155-173. Disponível em: www.dialogosmediterranicos.com.br. Acesso em: 16 mar. 2017.

${ }^{6}$ VERGER, Jacques. Homens e saber na Idade Média. Trad. Carlota Boto. Bauru, SP: EDUSC, 1999, p. 195.

${ }^{7}$ BARROS, José D’Assunção. O campo da história: especialidades e abordagens. 7. ed. Petrópolis, RJ: Vozes, 2010, p. 140.

${ }^{8}$ BOUHAÏK-GIRONÈS, Marie. "L'historien face à la littérature : à qui appartiennent les sources littéraires médiévales?". Actes des congrès de la Société des historiens médiévistes de l'enseignement supérieur public, 38 congrès, Île de France, 2007. Être historien du Moyen Age au XXIe siècle. p. 161. Disponível em: http://www.persee.fr/doc/shmes_1261-9078_2008_act_38_1_1950. Acesso em: 09 fev. 2017. 
Eustache Deschamps, esperando apontar de que forma sua obra poética pode ser considerada pela historiografia contemporânea como uma fonte bastante fecunda.

\section{A obra de Eustache Deschamps}

Eustache Deschamps, chamado Morel, foi um poeta nascido na região francesa da Champanhe no início da década de 1340 e morto nos primeiros anos do século XV. Ao versar sobre acontecimentos e comportamentos daquela sociedade, durante os reinados de Carlos V (1364-1380) e de Carlos VI (1380-1422), soberanos do reino da França que, juntamente com suas cortes, favoreceram a produção de não poucos homens de letras, o poeta champenois, que também usufruiu dos benefícios dos príncipes, deixou-nos muito da "realidade trivial" despercebido aos olhos dos historiadores da cultura na contemporaneidade.

Sua pena não foi apenas a de um poeta, mas a de um "poeta funcionário" ou "funcionário escritor" ${ }^{10}$, sem que isso tenha sido um demérito para a sua extensa produção de mais ou menos 82000 versos, e ainda outros escritos em prosa; ao contrário, Deschamps nos deixou uma obra que apresenta maturidade poética $e$ aguda sensibilidade para os acontecimentos à sua volta.

Enquanto funcionário do rei, emissário, poeta-guerreiro, historiador e confidente de Carlos VI e de Luís de Orléans, Eustache Deschamps tomava uma parte ativa nos acontecimentos políticos de seu tempo. Como a de seus contemporâneos[...] cujos escritos foram testemunhas de uma preocupação profunda com relação aos males contemporâneos, assim como de um esforço contínuo em colocar um fim nisso, a obra de Deschamps reflete um interesse similar pelas questões referentes à harmonia social, preocupação que duraria toda a sua vida. ${ }^{11}$ [Grifo nosso]

Considerar Eustache Deschamps como historiador, tal como faz a professora Susan J. Dudash da Universidade de Utah, no trecho citado acima, pode parecer um exagero. No entanto, neste ponto, tendemos a compreender a afirmação da pesquisadora, sobretudo porque Deschamps mostrou muito interesse pelos acontecimentos e relatou-os, como foi possível, nos versos de seus lais principalmente, longos poemas de caráter narrativo ${ }^{12}$.

9 ZINK, Michel. "Préface ». In: LACASSAGNE; LASSABATÈRE (orgs.). Les "dictez vertueulx " d'Eustache Deschamps. Forme poétique et discours engagé à la fin du Moyen Âge. Paris : PUPS, 2005, p. 7.

10 ZINK, "Préface ». In: LACASSAGNE; LASSABATÈRE (Org.), Les «dictez vertueulx »..., p. 7. ZUMTHOR, Paul. Essai de poétique médiévale. Paris : Editions du Seuil, 2000, p. 87.

${ }^{11}$ DUDASH, Susan J. "Eustache Deschamps: poète et commentateur politique ». In: LACASSAGNE, LASSABATÈRE (Org.), Les « dictez vertueulx »..., p. 147.

12 A exemplo disso, ver o lai 312, Le Lay du tresbon Connestable, em que a vida de Bertrand Du Guesclin é resumida em belos versos elogiosos. Para todas as referências aos textos de Deschamps, seguiremos a edição das Euvres Complètes d'Eustache Deschamps par le Marquis de Queux de Saint- 


\section{Como observou Marc Bloch:}

A diversidade dos testemunhos históricos é quase infinita. Tudo que o homem diz ou escreve, tudo que fabrica, tudo que toca pode e deve informar sobre ele. É curioso constatar o quão imperfeitamente as pessoas alheias a nosso trabalho avaliam a extensão dessas possibilidades. É que continuam a se aferrar a uma ideia obsoleta de nossa ciência: a do tempo em que não se sabia ler senão os testemunhos voluntários ${ }^{13}$.

Toda a poesia de Deschamps, assim como outra expressão literária de qualquer período da história, nos informa sobre o seu tempo e seus contemporâneos. Ainda que voluntários, os versos de Deschamps são testemunhos que podem contar e muito aos historiadores de nossos dias, bastam-nos as perguntas corretas, segundo uma hipótese de trabalho como a que propôs Jacques Le Goff, ao retomar Foustel de Coulanges e Lucien Febvre, "eles [os documentos] só respondem às questões do historiador e este deve abordá-los não com os preconceitos e ideias retrógradas, mas com hipóteses de trabalho [...]. O que quero afirmar é o caráter multiforme da documentação histórica [...]". ${ }^{14}$

Conforme vimos, ocupando diferentes postos junto à monarquia francesa, o poeta pôde circular pelos paços e aprimorar seu senso de observação, construindo para si próprio uma carreira de renome: estudou direito em Orléans; a partir de 1368 esteve no entorno de Carlos V como escudeiro, oficial de armas em 1375, oficial de justiça de Valois e de Senlis; e já sob Carlos VI, em 1381, nomearam-no castelão de Fismes e membro de uma embaixada de 1384 a 1386 na região em que hoje se situam a Hungria e a Croácia. E ainda que, durante todo esse tempo, não possuísse nenhum título nobiliárquico, o que ocorreu apenas em 1389, quando senhor de Barbonval, Deschamps não deixou de escrever abertamente sobre seus senhores, como a iguais, repreendendo comportamentos e exigindo aquilo que lhe haviam prometido. Não se absteve igualmente de cantar-lhes as virtudes de forma grandiosa, o que notamos, de modo singular, nos textos em que a menção à figura do rei Carlos $\mathrm{V}$, o Sábio, e à de seu mais ilustre condestável ${ }^{15}$, Bertrand Du Guesclin, são marcantes, como veremos mais adiante.

Não obstante, o senhor que melhor o protegeu foi o segundo filho de Carlos V, o duque Luís de Orléans ${ }^{16}$, exemplo de "prouesce et sens", a quem o poeta serviria até quase o fim de sua vida. O que marcou a conclusão de sua carreira, por volta de

Hilaire et Gaston Raynaud, Paris: Firmin-Didot, 11 vol., 1878-1903, doravante referida como Euvres Complètes.

${ }^{13} \mathrm{BLOCH}$, Marc. Apologia da história, ou, O ofício de historiador. Trad. André Telles. Rio de Janeiro: Jorge Zahar Ed, 2001, p. 79-80.

${ }^{14}$ LE GOFF, Jacques. Histoire et mémoire. Paris: Ed. Gallimard, 1988, p. 299.

${ }^{15}$ Connétable, em francês, designa o posto de maior importância que um militar da época poderia alcançar, posição que Du Guesclin ocupou de 1370 a 1380, quando de sua morte em campanha pela região da Auvergne, centro-sul da França.

${ }^{16}$ HEGER, Henrik. "Eustache Deschamps, 1344-1404 » In: GAUVARD, Claude; LIBERA, Alain; ZINK, Michel (orgs.). Dictionnaire du Moyen Âge. 4e ed. Paris: PUF, 2012, p. 501. 
1400, já afastado das atividades que exercia na corte, foi a submissão a uma aposentadoria difícil, vindo a falecer apenas alguns anos depois.

Ao longo de quase quarenta anos, sua atividade de escrita literária se deu com autonomia, até mesmo com intransigência, e a função de poeta reconhecido concedeu a Deschamps o poder de, com seus versos, estar acima das leis dos soberanos. Ao falar da realidade concreta que o cercava, nem sempre foi elogioso, nem tampouco solene com relação a seus senhores, como já apontamos. É claro, seus textos podem ter circulado de maneira anônima ${ }^{17}$, o que talvez tenha facilitado sua "sinceridade" ao escrever sobre a aristocracia cortesã, tê-la como interlocutora e ainda comentar suas decisões políticas. Ao estar baseada sobre os acontecimentos da vida, sua poesia de "moralização ou de moralidade" não esteve longe da sátira que é mestre em dar lições ${ }^{18}$, conforme a balada 208 a seguir:

L'un pié dedenz, s'aucun meschief lui sourt,

Fait bon avoir pour grace demander,

L'autre dehors si aucun mal y acourt,

Afin qu'on puist le peril eschiver ;

Vivre du sien, et qu'on puist demourer,

En paix de cuer: autrement ne m'assens

D'avoir a court un pié hors et l'autre ens.
Um pé dentro, se algum mal lhe surge,

É bom por graça rogar,

O outro fora se algum mal ocorre,

A fim de que possa do perigo esquivar;

Viver do seu, e que possa habitar,

Em paz de coração: de outra forma não

Ter na corte um pé fora e outro dentro. ${ }^{19}$

Entretanto, cremos que conceber a obra de Deschamps como um reflexo direto de seu conselho político a ponto de considerá-la um "projeto de unificação dos franceses e o de uma cristandade unificada na perspectiva de uma paz completa e durável para todos" ${ }^{20}$, desvirtuaria a abordagem de sua poética. É claro, foi um poeta que sim, deu voz às camadas mais desfavorecidas da população francesa, personificou a França, dando-lhe uma opinião que condenou muitas vezes as decisões de governo, principalmente durante o reinado de Carlos VI, e não poupou nem mesmo os combatentes dos conflitos contra os ingleses, mantendo uma visão bastante pessimista sobre a sociedade, mas que defendeu com vigor a imagem do rei precedente, cujo epíteto, o Sábio, Deschamps colaborou em perpetuar ${ }^{21}$.

\footnotetext{
${ }^{17}$ Embora saibamos que a maior parte da obra de Deschamps tenha sido compilada postumamente, seguindo critérios para uma classificação formal dos textos, sob a supervisão do copista Raoul Tainguy, conforme o manuscrito conservado na Biblioteca Nacional da França, BN fr. 840, datado do primeiro quarto do século $\mathrm{XV}$, há indícios como dedicatórias e ilustrações que revelam que o poeta também oferecia seus manuscritos aos nobres a quem servia, assegurando sua difusão nas cortes, como por exemplo a tradução-adaptação do texto latino do papa Inocêncio III, Double lai de fragilité humaine, dedicado a Carlos VI em 1383. O manuscrito, preservado pela Biblioteca Nacional, BN fr. 20029, traz 55 ilustrações, dentre elas, a que representa o poeta oferecendo a obra ao rei (Cf. http://gallica.bnf.fr/ark:/12148/btv1b8454691k/f1.image.r=Eustache\%20Deschamps.langFR. Acesso em: 16 mar. 2017).

${ }^{18}$ ZINK, M. «Préface » In: LACASSAGNE; LASSABATÈRE (orgs.), Les « dictez vertueulx »..., p. 8.

${ }^{19}$ Apresentamos aqui uma tradução apenas semântica.

20 DUDASH, "Eustache Deschamps: poète et commentateur politique ». In: LACASSAGNE; LASSABATÈRE (orgs.), Les « dictez vertueulx »..., p. 148.

${ }^{21}$ Por exemplo, em seu poema Fiction du lion, Deschamps tece severas críticas ao governo de Carlos VI realizando na verdade um imenso elogio ao pai, Carlos V, o "noble lion" que, aclamado por todos os franceses, seria o verdadeiro modelo de justiça e bondade (Cf. CEuvres Complètes, vol. 11, p. 160).
} 
Embora tudo o que foi dito acima seja premente em quase toda a obra de que falamos aqui, devemos considerar que antes de desejar unir os franceses ou a cristandade latina, Deschamps cantou os poderosos, a quem devia fidelidade, pois mesmo que em certos textos eles apareçam detratados, foram dignos de figurar em seus versos. Assim, não acreditamos que a obra do poeta champenois seja representante autônoma de um discurso político que estivesse totalmente desvinculado daquele da aristocracia, pois, os "homens que participam desta sociedade política influenciadora, mas também vítima das políticas régias faziam suas opções políticas em função de um jogo político amplo que envolvia a rede linhagística e vassálica de praticamente todo o Ocidente latino"22.

A obra de Deschamps, aproximando-nos agora de suas características formais, tal como foi compilada ainda no século XV, apresenta cinco grandes formas fixas: a balada, o canto real, o rondó, o virelai e o lai, formas que "se tornaram o molde ideal dessa cristalização estética, no qual pode se difundir e diluir uma nova subjetividade poética, uma nova reflexividade lírica" ${ }^{23}$. Dessas formas, todas trabalhadas com maestria por Deschamps, a mais conhecida é a balada, cujos temas variados mostram a vivacidade $e$ a atenção com que o poeta se voltou ao elemento mais instigante daquele período: o comportamento humano, elemento protagonista nos três temas bem distintos das baladas do poeta francês, o amor, as armas e a moralidade. Essas designações, aliás, guiaram em parte a edição das Euvres Complètes realizada no final do século $\mathrm{XIX}^{24}$. Ademais, naquele final de século XIV, a balada e o rondó, ao constituírem-se como gênero literário, perdiam suas referências com o bal e a ronde $e^{25}$, respectivamente, salientando a separação entre a performance musical, com as danças, e o trabalho textual que Deschamps ajudou a estabelecer como veremos nas linhas a seguir.

O poeta champenois nos deixou um trabalho de teoria poética em prosa em que explica e exemplifica as cinco formas fixas de sua poesia. Trata-se da primeira arte de versificação em língua francesa (en langue d'oïl ${ }^{26}$ ), a Art de dictier et de fere chançons, de novembro de $1392^{27}$.

${ }^{22}$ FERNANDES, Fátima R. "Usurpações, casamentos régios, exílios e confiscos, as agruras de um nobre português no século XIV", Rev. História Helikon, Curitiba, v. 2, n. 2, 2 semestre/2014, p. 15. Disponível em: http://www2.pucpr.br/reol/pb/index.php/helikon?dd99=actual. Acesso em: 17 mar. 2017.

${ }^{23}$ GALDERISI, Claudio. «Discontinuité des poétiques - La discontinuité des poétique au Moyen Âge ». In : LESTRINGANT, Frank; ZINK, Michel. Histoire de la France littéraire - Naissances, Renaissances, Moyen Âge - XVI ${ }^{e}$ siècle. $3^{\text {e }}$ ed. Paris : PUF, 2009, p. 793.

${ }^{24}$ CEuvres Complètes d'Eustache Deschamps par le Marquis de Saint-Hilaire et Gaston Raynaud, Paris: Firmin-Didot, 11 vol., 1878-1903. Ainda hoje, trata-se da edição mais bem difundida entre os estudiosos de Deschamps.

${ }^{25}$ GROS, Gérard. "Le lyrisme - Lyrique au Moyen Âge ». In : LESTRINGANT; ZINK. Histoire de la France littéraire - Naissances, Renaissances, Moyen Âge - XVI ${ }^{e}$ siècle. $3^{e}$ ed. Paris: PUF, 2009, p. 909.

${ }^{26} \mathrm{O}$ professor do Collège de France, Michel Zink, já citado anteriormente, é quem faz menção à obra de Guilhem Molinier, Las leys d'amors, em língua provençal, como o primeiro tratado de poética escrito na França (Cf. ZINK, M. Littérature française du Moyen Âge. Paris: Quadrige/PUF, 2004, p. 275). No entanto, a obra de Molinier de 1356, versa não apenas sobre a poética provençal, mas também, e de modo bastante disperso, sobre retórica, teologia, considerações morais concernentes ao ato de dar e receber conselhos, etc. (Cf. BRUNEL, Clovis. Las Leys d'Amors. Manuscrit de l'Académie des Jeux Floraux publié par Joseph ANGLADE. Toulouse, Privat,1919-1920.(Bibliothèque méridionale publiée sous les auspices de la Faculté des lettres de Toulouse, 1re série, t. XVII XX)., Bibliothèque de l'école 
Eustache Deschamps é uma grande figura da lírica francesa, já que ele contribuiu para fixar as formas consideradas como tipicamente medievais por sua reflexão teórica na Art de dictier [...]. Em seus inúmeros poemas, as diferenças de versificação, o plurilinguismo $e$ a polifonia são técnicas do descontínuo que respondem à quebra do quadro lírico cortês em uma multiplicidade de temas políticos e pessoais. O poeta reproduz assim pela heterogeneidade de sua obra sua visão apocalíptica do mundo. ${ }^{28}$

$\mathrm{Na}$ Art de dictier, o letrado se refere à música, compreendida entre as sete artes liberais (a soma do trivium e do quadrivium), estabelecendo uma importante diferença entre o que ele considera como música artificial e música natural.

Mas antes, o poeta abre seu tratado afirmando que o aprendizado dessas artes fora privilégio apenas de nobres, "antigamente, somente aqueles de nobre linhagem é que ousavam aprender as sete artes", mas, na sua temporalidade, talvez mesmo aqueles que não pertenciam a "noble lignie" poderiam se exercitar nelas, até mesmo as crianças. Isso podemos apontar, visto que ao elencar e explicar, ainda que brevemente, as artes liberais, com exceção da retórica, o autor refere-se a grupos de trabalhadores: a geometria para os que constroem castelos, embarcações e objetos variados, ou seja, artesãos e arquitetos; a aritmética para os que trabalham com dinheiro e mesmo os astrônomos, a quem também o conhecimento da astronomia propriamente dita era fundamental. Dessa forma, podemos dizer que o poeta era de fato um bom observador da sociedade, contemplando outras camadas sociais e não apenas a da alta nobreza, todas em sensível transformação, embora ainda exemplos da estratificação vigente. Deschamps ainda aproxima a música da medicina, afirmando que quando os trabalhadores das outras artes estivessem cansados ou tristes, pela doçura da música seriam "medicados e reanimados, vindo assim a ser mais hábeis para estudar e trabalhar as outras seis artes" 29 .

Após explanar sobre a sétima arte de tal maneira, o autor prossegue na explanação de seu pensamento sobre a música, detalhando a diferença que acreditava haver entre a artificial e a natural. A música artificial seria aquela produzida pelos instrumentos musicais que "le plus rude homme du monde" poderia tocar. Já a música natural não seria uma arte a ser aprendida, mas uma ciência natural, uma "música de boca proferindo palavras metrificadas", as declamações, uma arte que, próxima à retórica, não poderia ser executada por qualquer pessoa.

des chartes, 1921, vol. 82, n 1, pp. 186-188. Disponível em: http://www.persee.fr. Acesso em: dez. 2014). Trata-se sem dúvida de obra importante para a filologia provençal, todavia não se iguala em objetividade e organização à obra de Deschamps.

${ }^{27}$ Euvres Complètes, vol. 7, p. 266-292.

28 JOBERT-DAUPHANT, Clotilde. La Poétique des CEuvres complètes d'Eustache Deschamps (ms. BN fr. 840): composition et variation formelle. État de Recherche, Perspectives Médiévales, Revue d'épistémologie des langues et littératures du Moyen Âge, 34, 2012. Disponível em: http://peme.revues.org/1917. Acesso em: 05 dez. 2014.

${ }^{29}$ Euvres Complètes, vol 7, p. 269. 
Deschamps justifica seu tratado como o conteúdo a ser dominado por aqueles com inclinação à ciência da música natural, portanto, o que o autor sugere com sua lição é que os "iniciados" aprimorem seus talentos natos conhecendo em detalhes as diferentes maneiras de compor baladas, canções, rondeis e lais, sabendo metrificar, contar sílabas, compor rimas, femininas ou masculinas, enfim, que sejam capazes $e$ bem-sucedidos na arte da versificação, assim como ele mesmo o foi.

O rompimento com a música instrumental faz de Deschamps o "primeiro autor a abandonar de modo sistemático o acompanhamento musical" 30 para a apresentação de seus textos, pois, conforme seu pensamento:

Onde o canto da música artificial não tiver lugar, como entre senhores e damas estando na sua intimidade e secretamente, será ali que a música natural poderá ser dita e recordada por um homem sozinho, com seus lábios, ou que algum livro poderá ser lido com coisas agradáveis diante de um doente, $e$ outros casos semelhantes em que o canto musical não tiver lugar pela importância daquele, e a triplicidade das vozes pelos tenores e contra tenores necessários àquele canto proferido por duas ou três pessoas para a perfeição do referido canto. ${ }^{31}$

Segundo as palavras do letrado, fica bastante evidente que a leitura silenciosa $e$ privada já era realidade na corte em que o poeta atuava, e que a experiência estética do leitor em contato pessoal com o texto, poderia até mesmo servir de consolo aos doentes, como ele afirma. É muito interessante imaginar quais versos estiveram nos lábios dos senhores e das damas da corte francesa naquele final do século XIV: podemos dizer que eles se divertiam, esqueciam-se dos problemas, sonhavam com realidades diferentes, zombavam de seus pares, louvavam os monarcas ou choravam a morte dos valentes através dos versos de seus protegidos sussurrados em secreto? Tudo isso se mostra bastante provável ${ }^{32}$.

\section{O cavaleiro Bertrand Du Guesclin nos versos de Eustache Deschamps}

A propósito, verticalizando um pouco mais a abordagem da obra poética de Eustache Deschamps, concentremo-nos em suas baladas, dentre elas, a mais célebre, aquela sobre a morte do condestável ${ }^{33}$ Bertrand Du Guesclin, ocorrida em julho de

\footnotetext{
${ }^{30}$ HEGER, « Eustache Deschamps, 1344-1404 » In: GAUVARD; LIBERA ; ZINK, (orgs.), Dictionnaire du Moyen Âge..., p. 502.

${ }^{31}$ Euvres Complètes, vol. 7, p. 272.

${ }^{32}$ Segundo Jacques Verger, o acesso aos manuscritos que compunham as bibliotecas principescas era reservado aos "familiares dos soberanos, seus visitantes distintos e seus conselheiros políticos". A biblioteca do rei Carlos V contava com pouco menos de 1300 volumes no ano de sua morte em 1380 (VERGER, Homens e saber..., p. 118-119).

33 Connétable em francês, o termo derivou da expressão latina que designava o responsável pelos estábulos de um senhor, comes stabuli, conde do estábulo. Essa transformação do vocábulo denota a importância que o cargo foi alcançando a partir do século XII para então referir aquele que depois do rei, era chefe das hostes francesas, comandante supremo sobre os comendadores e marechais do reino,
} 
1380. Acometido de um mal súbito, quando em campanha na região hoje denominada Auvergne-Rhône-Alpes, durante o sítio ao castelo de Châteauneuf-deRandon tomado por ingleses, no contexto da Guerra dos Cem Anos (1337-1453), o militar perdeu a vida e passou a figurar nas linhas de poemas, crônicas e canções de gesta $^{34}$.

No que se refere aos aspectos formais dessa expressão poética, podemos dizer que as baladas são poemas curtos, divididos em três estrofes de oito, nove ou dez versos decassílabos, geralmente com a repetição de um mesmo verso ao final de cada estrofe como refrão. Pode haver ou não uma estrofe de quatro ou cinco versos compondo o envio, parte final do poema em que o eu lírico se dirige a um interlocutor, o Príncipe, por exemplo, sendo que foi justamente sob a impulsão de Deschamps que o conjunto ficou assim definido ${ }^{35}$. A estrofe ainda pode ser organizada opondo os versos longos, os decassílabos, a um verso mais curto, de seis ou sete silabas, em que surge a terceira rima. Quanto a elas, podem ser cruzadas, seguindo o esquema abab/bc/cdcd, como no caso da balade de moralitez 206, em homenagem ao condestável, conforme podemos observar a seguir.

Esta balada está entre os oito poemas de Eustache Deschamps em que o cavaleiro bretão, Du Guesclin, aparece nominalmente, embora haja outros em que o condestável parece ser o personagem aclamado ${ }^{36}$.

Estoc d'oneur et arbres de vaillance Cuer de lyon esprins de hardement, La flour des preux et la gloire de France, Victorieux et hardi combatant,

Saige en voz fais et bien entreprenant, 5

Souverain homme de guerre,

Vainqueur de gens et conquereur de terre,

Le plus vaillant qui onques fust en vie,

Chascun pour vous doit noir vestir et querre:

Plourez, plourez flour de chevalerie.

10

O Bretaingne, ploure ton esperance,

Normandie, fay son entierement,

Guyenne aussi, et Auvergne or t'avence,

Et Languedoc, quier lui son mouvement.
Raiz de honra e árvore de pujança

Coração de leão cheio de ousadia,

A flor dos valentes e a glória da França,

Vitorioso e ousado combatia,

Era sensato nos feitos e bem fazia,

Soberano homem de guerra,

Vencendo gentes e conquistando terra,

$\mathrm{O}$ mais valente que jamais existiria,

Cada um por vós deve enlutar-se e clamar:

Lamentai, lamentai, flor da cavalaria.

Ó Bretanha, chora tua esperança,

Normandia, dá honra a teu ausente,

Guiena também, e Auvergne ora, avança,

E Languedoc, pede dele seu presente.

ou seja, o mais alto cargo que um militar da época poderia obter (Cf. Dictionnaire encyclopédique de la noblesse de France, p. 438-440, t. 1, 1816 e o site do Dictionnaire du Moyen Français, verbete connétable, ver: www.atilf.fr/dmf/).

${ }^{34}$ Bertrand Du Guesclin é, por exemplo, o herói de uma canção de gesta tardia composta entre os anos de 1380 e 1385 pelo trovador Cuvelier, La chanson de Bertrand Du Guesclin. Logo a canção recebeu uma versão em prosa que se tornou fonte de muitos dos escritos sobre o condestável nos séculos seguintes, iniciando uma longa tradição de biografias sobre o militar bretão.

${ }^{35}$ HEGER, « Ballade ». In: GAUVARD; LIBERA; ZINK (orgs.), Dictionnaire du Moyen Âge..., p. 127.

${ }^{36}$ BOUDET, Jean-Patrice e MILLET, Hélène. Eustache Deschamps en son temps. Collection Textes et Documents d'Histoire Médiévale. Paris: PUPS, 1997, p. 58. 
Picardie, Champaigne et Occident 15

Doivent pour plourer acquerre

Tragediens, Arethusa requerre

Qui en eaue fut par plou convertie,

Afin qu'a touz de sa mort les cuers serre :

Plourez, plourez fleur de chevalerie.

20

Hé! gens d'armes, aiez en remembrance

Vostre père, vous estiez si enfant ;

Le bon Bertran, qui tant ot de puissance,

Qui vous amoit si amoureusement ;

Guesclin crioit ; priez devotement

25

Qu'il puist paradis conquerre ;

Qui dueil n'en fait et qui ne prie il erre,

Car du monde est la lumiere faillie :

De tout honeur estoit la droicte serre :

Plourez, plourez flour de chevalerie.

30
Picardia, Champanha e Ocidente

Devem pelo choro transformar Dramaturgos, Aretusa virá buscar Que em lágrimas a vida passaria, Sua morte todos os corações venha apertar: Lamentai, lamentai, flor da cavalaria.

Hei! Gentes de armas, tenhais na lembrança

Vosso pai, vós éreis sua posteridade;

$\mathrm{O}$ bom Bertrand, que tanto teve pujança,

Que tanto vos teve amado de verdade;

Guesclin bradava; orai com sinceridade

Que ele possa paraíso conquistar;

Quem não se enlutar, está a se enganar,

Pois do mundo está a aurora fria:

Com toda honra fora a direita firmar:

Lamentai, lamentai, flor da cavalaria. ${ }^{37}$

Não se trata do texto mais antigo de Deschamps sobre o condestável, pois há pelo menos três poemas cujos versos elogiosos foram feitos ainda quando o valente bretão vivia, são as baladas 222 e 239 e o canto real 362, todos compostos entre os anos de 1372 e 1380. Das homenagens póstumas, sabemos que o único poema a que se pode atribuir uma data, é a balada 1125 , que remonta a $1396^{38}$, portanto, não se sabe com exatidão em que ano a balada que estudamos aqui foi composta.

A temática característica desses textos é a valentia de que Bertrand Du Guesclin fez prova durante os conflitos da guerra entre franceses e ingleses e seus respectivos aliados. O desempenho do militar bretão, tema da balada, remete à sua atuação principalmente a partir do final da década de 1360, em que o condestável, enviado à Castela, combateu, ao lado de Henrique Trastâmara, Pedro I de Castela, chamado de o Cruel $^{39}$. Louvado como modelo dos valores caros à cavalaria, Du Guesclin figura nos textos de Deschamps como exemplo de uma nova conduta para os combatentes que faziam parte da cavalaria francesa, ainda que para isso tenha se servido de estratégias nem sempre condizentes com a tradição. $\mathrm{O}$ que podemos inferir é que a

${ }^{37}$ A tradução que propomos buscou aliar forma e sentido, infelizmente não pudemos preservar com fidelidade a versificação e nem a totalidade do esquema de rimas.

${ }^{38}$ BOUDET; MILLET, Eustache Deschamps en son temps..., p. 58.

39 As campanhas castelhanas de Bertrand Du Guesclin (1366-1369) serviram a dois fins muito proveitosos ao monarca francês Carlos V: livrar a França das companhias de mercenários desocupados que, entre uma batalha e outra, assolavam o interior do país, com pilhagens, destruição e violência contra os habitantes das regiões por onde passavam, e combater o inimigo inglês ainda fora dos domínios franceses, o Príncipe Negro, mais precisamente, que apoiava Pedro I de Castela contra o irmão bastardo, Henrique Trastâmara na luta pela coroa. O apoio de Du Guesclin foi fundamental à dinastia trastamarista, vencedora do conflito, após o assassinato de Pedro I, em Montiel no ano de 1369. 
própria cavalaria como valor militar e eficiência em situação de guerra passava por transformações.

Deschamps utilizou o personagem de Du Guesclin como personagem ilustre quase contemporâneo de seus leitores. [...] O poeta não se contenta em exortar o rei e seus sujeitos a uma nova vitória contra os ingleses. Como outros autores de sua época, ele instrumentaliza a vida de um personagem, mesmo que ambíguo, para mostrar a que ponto a virtude é desejável, possível, mas difícil na sua época. Para Deschamps, o modelo moral por excelência oferecido a seus leitores, príncipes ou não, é representado por um guerreiro, ainda que ele tenha defendido tanto a paz quanto a guerra ${ }^{40}$.

A ideia desenvolvida na citação acima corrobora com o que consideramos ser relevante para se pensar a poesia de Deschamps sobre Du Guesclin: uma exaltação do serviço à coroa francesa, algo de que a aristocracia da época, ainda muito arraigada aos valores feudais, precisava ser "convencida". Nada mais eficaz, portanto para isso, do que poemas de versos concisos e bastante diretos que estavam circulando nesse meio.

A balada 206 faz essencialmente dois movimentos. O primeiro, e que é mais evidente de fato, se compõe dos versos de Deschamps que louvam o personagem $\mathrm{Du}$ Guesclin pelos vários atributos que lhe conferem: valentia, força, sabedoria, características fundamentais para um militar ocupando a connétablie. Em segundo lugar, nas duas últimas estrofes, Deschamps convoca as regióes por onde o condestável atuou em favor do reino francês e nas quais possuía bens senhoriais e também as "gens d'armes", a flor da cavalaria, para que agora, órfãos de seu "pai", chorem e lembrem-se de Du Guesclin que tanto os amou.

É preciso observar que a balada

Conhece no fim da Idade Média um tal sucesso que chegamos a procurar na eficácia desse esquema a adequação de uma fórmula a certas disposições mentais da época [...]. Esse gabarito convém igualmente à narrativa de um pequeno drama. A balada se adapta à intenção discursiva como ao projeto narrativo ${ }^{41}$.

Com essa característica, cabe dizer que a poesia de Deschamps também colaborou com a Escrita da história na França tardo-medieval, pois ao lado da produção cronística bastante demandada pela monarquia do período, seus versos também se abriam à celebração e à memória, uma "ligação entre a forma literária e a

${ }^{40}$ DAUPHANT, «Qu'est devenu David et Salemon? » Les Hommes illustres dans la poésie d'Eustache Deschamps ", Questes, Revue pluridisciplinaire d'études médiévales, 17 | 2009, p. 99-119. Disponível em: http://questes.revues.org/1648. Acesso em: 18 mar. 2017.

${ }^{41}$ GROS, «Le lyrisme... », p. 912. 
intencionalidade do discurso, revelador de uma dupla realidade do personagem" ${ }^{42}$. Pois, como afirma Paul Zumthor, "a voz poética é, ao mesmo tempo, profecia e memória" capaz de "projetar a aventura e eternizar o acontecimento" ${ }^{3}$. Ademais, sua balada faz lembrar ainda a descrição das cerimônias fúnebres realizadas em honra a Du Guesclin em maio de 1389, a pedido de Carlos VI na basilica de Saint-Denis, necrópole real, onde o condestável havia sido sepultado. A narrativa dessa cerimônia feita em latim pelo monge Michel de Pintoin, na Chronicorum Karoli Sexti ${ }^{44}$, relata que os ilustres senhores que dirigiram o luto, dentre eles o condestável Olivier de Clisson, que seguiu a Du Guesclin na função, o marechal Luís de Sancerre e o irmão de Du Guesclin, estavam todos vestidos de preto, como para o funeral de um amigo, nas palavras do religioso. Outros personagens da alta nobreza também estiveram presentes, o rei Carlos VI que acompanhava o prelado até a entrada do coro e os príncipes de sangue, entre os quais, Luís de Orléans que, lembremo-nos, foi um dos protetores do poeta.

O detalhe mais marcante da cerimônia, no entanto, foram as palavras do bispo de Auxerre, o oficiante que celebrou os trabalhos: segundo o cronista, o bispo declarou que $\mathrm{Du}$ Guesclin havia sido a flor da cavalaria francesa e o modelo dos valentes (preux), enumerando seus feitos de armas, relembrando o tamanho bem que havia feito à França. Dirigiu-se ainda aos cavaleiros presentes advertindo que a cavalaria havia sido instituída no interesse de todos para servir à utilidade pública do reino. É possível, portanto, assinalar que Deschamps possa ter assistido à cerimônia e diante do ritual solene, bastou-lhe a arte de bem compor uma outra balada, conforme a estrofe primeira da balada 1125 (v. 4-12) que transcrevemos abaixo:

Les prouesces que fist li bon Bertrans, Connestable de Guesclin, qui engrans Fut de garder l'utilité publique, Et qui maintint si sa guerre punique Sur les Anglois, que France reformée En fut et est par mainte belle armée Faitte a son temps, et mourut en la guerre De son segnour ; moult fut sa mort plourée : Noble chose est de bon renom acquerre!
As proezas que fez Bertrand, Condestável Du Guesclin, que desejoso Foi de guardar a utilidade pública, E que manteve assim sua guerra púnica Sobre os ingleses, que França reformada Foi e é por grande bela armada

Feita em seu tempo, e morto na guerra De seu senhor; muito foi sua morte chorada: Nobre coisa é de bom renome adquirida! ${ }^{45}$

A realidade concreta fica bem evidente nas palavras de Deschamps quando conseguimos imaginar a cerimônia, que ainda contou com cavaleiros montados $e$ armados, levando as bandeiras de Du Guesclin, depositando suas armas no altar e recebendo o toque do bispo sobre suas cabeças, tudo feito lentamente, cerimoniosamente, como relata o monge cronista. Todos os presentes mantinham as cabeças baixas e se ousavam falar, eram palavras de louvor, e não é difícil ver, alguns

${ }^{42}$ LASSABATÈRE, Du Guesclin - Vie et fabrique d'un héros médiéval. Paris: Perrin, 2015, p. 421.

${ }^{43}$ ZUMTHOR, Paul. A letra e a voz. A "literatura" medieval. São Paulo: Companhia das Letras, 1993, p. 139.

${ }^{44}$ A Crônica do Religioso de Saint-Denis, como é mais conhecida, compreende o reinado de Carlos VI, de 1380 a 1422.

45 Tradução semântica. 
deles ao menos, com os olhos marejados de lágrimas pelo condestável, ainda que já houvesse passado quase uma década de sua morte. Mas quem foi e o que fez esse valente militar vindo da média nobreza bretã para merecer tamanha honra?

Nascido por volta de 1320 na região da Bretanha, Du Guesclin foi o primogênito de dez irmãos e desde cedo mostrou-se combativo e ávido por ações guerreiras, fazendo das brincadeiras de criança um treino precoce para os torneios de que veio participar quando adolescente, à revelia dos pais. Um pouco mais tarde, obtendo o apoio de um tio e vencendo combates importantes nos jogos, Du Guesclin pôde contar com a ajuda financeira dos parentes para adquirir suas armas, elementos fundamentais para a participação das justas oficiais que ocorreriam no ducado naqueles anos. Foi por suas habilidades $e$ incrivel força que o jovem bretão se destacou, chamando a atenção daquelas autoridades. No entanto, Du Guesclin só foi adubado cavaleiro por Carlos de Blois, candidato à sucessão do ducado da Bretanha e seu primeiro senhor, por volta de 1357, com a idade já um tanto avançada para tal cerimônia, sobre a qual não se tem nenhum relato confiável. Aliás, não sabemos com segurança se foi de fato Carlos de Blois a elevar Du Guesclin à condição de cavaleiro $^{46}$, embora isso tenha ocorrido. Algum tempo depois, foi nomeado tenente de regiões importantes como a Normandia, Anjou e Marne. Mudança considerável para quem se iniciou nos combates liderando simples bandos de soldados ávidos por aventurar-se a derrotar alguns inimigos ingleses ${ }^{47}$.

As circunstâncias da coroação de Carlos V na cidade de Reims, em 19 de maio de 1364, deram muita visibilidade a Du Guesclin. Os inimigos da coroa francesa haviam se reunido para impedir que o delfim Carlos seguisse de Paris a Reims a fim de ser sacramentado rei. Porém, as forças francesas, encabeçadas pelo comandante $\mathrm{Du}$ Guesclin, garantiram a linhagem dos Valois no poder do reino da França, com a vitória na Batalha de Cocherel três dias antes da coroação. Estaria ali determinada a série de êxitos que ligaria a vida do rei Carlos $\mathrm{V}$ à de seu fiel comandante, $\mathrm{Du}$ Guesclin? Seria o triunfo das virtudes cavaleirescas sobre qualquer outra, segundo o que nos diz, por exemplo, a mulher de letras por excelência do medievo, e discípula de Eustache Deschamps, Christine de Pizan ${ }^{48}$ ?

${ }^{46} \mathrm{O}$ historiador e biógrafo de Du Guesclin, George Minois, apresenta em seu volume, publicado em 1993, a transcrição de um documento em que o então delfim, Carlos V, teria designado um pagamento a Du Guesclin no valor de 200 libras por sua lealdade e valentia na defesa da cidade de Rennes contra os ingleses: "Savoir faisons que, pour considération de la loyauté et vaillance de nostre amé et féal monseigneur Bertran du Guerclin chevalier, sire de Broon [...] avons doné et otroié, donnons et otroions audit monseigneur Bertran deux cenz livres tournois de rente [...] sur les émoluments et revenus de la ville de Beuvron [...] sur la recette ordinaire ou extraordinaire de la vicomté d'Avranches." O documento traz a data de 6 de dezembro de 1357 e designa Du Guesclin como cavaleiro a quem as cidades deveriam pagar pensão, como devolução de impostos ao reino, MINOIS, George. Du Guesclin. Paris: Fayard, 1993, p. 473.

${ }^{47} \mathrm{Na}$ década de 1340, ainda na Bretanha, Du Guesclin liderou partidários do reino francês contra os ingleses na floresta de Brocéliande, sua atuação, nada convencional pelos códigos da cavalaria, imaginamos, rendeu-lhe a alcunha de Dogue Noir de Brocéliande, cuja fama se espalhou rapidamente entre os opositores.

${ }^{48}$ Christine de Pizan recebeu em 1403 de Filipe, duque da Borgonha, a incumbência de escrever uma biografia real oficial do rei Carlos V. A obra foi terminada no ano seguinte e recebeu por título Le livre des fais et bonnes meurs du Sage Roy Charles V, ela contém em uma de suas divisões um verdadeiro 
O que sabemos é que Du Guesclin, após retornar exitoso de suas campanhas em Castela, foi nomeado condestável das hostes reais em outubro de 1370, função de prestígio absoluto para um militar naqueles anos, o que nos leva a concluir que a função não seria concedida a nenhum soldado indignamente. A legitimação que tal título conferia a Du Guesclin lhe dava autoridade e liberdade para comandar em campo de batalha de modo a garantir que Carlos $\mathrm{V}$ fosse vitorioso.

Porém, se a figura de Du Guesclin ainda hoje suscita controvérsias, havemos de melhor examinar as fontes chamadas de oficiais somadas às de caráter literário para que não incorramos em erros $^{49}$, e não podemos tampouco ceder à ausência de documentos, porque a história "deve ser feita [...] com tudo o que a engenhosidade do historiador pode lhe permitir utilizar para fabricar seu mel, em detrimento das flores usuais" 50 .

Certamente, com relação à cavalaria e aos postos oficiais próximos ao rei, devemos considerar que a sociedade daquele final de século XIV já não se mostrava assim tão limitada aos laços de sangue, assim "só a compreensão deste contexto e suas regras originais nos permitem compreender as opções de uma elite que se transforma nestes séculos finais da medievalidade e vai trocando o respeito ao sangue pela primazia do serviço ao rei" ${ }^{51}$. Ao que devemos acrescentar a manutenção do bem comum, ou da utilidade pública, como sugere Deschamps nos versos citados acima.

$\mathrm{O}$ historiador Bernard Guenée ainda afirma que os reinados de Carlos $\mathrm{V}$ e de Carlos VI se configuraram como um período insigne na história do renome. Ele continua e sustenta que ser nomeado chefe das hostes reais exigia ser um "personagem de alto escalão, muito próximo do rei pelo seu nascimento",

mas a situação dramática em que estava a França, o que lhe [a Du Guesclin] impunha a connétablie apesar de seu humilde nascimento, não foi, em última análise, nem a valentia, nem a sorte. Foi, todos concordavam, o favor que ele havia obtido em todos os meios [...] ele subiu alto pela voz comum do reino, pelo favor do mundo. O dia 2 de outubro de 1370 marca o notável triunfo do renome, da celebridade, da popularidade, sobre o nascimento. [Ainda

\footnotetext{
compêndio sobre a cavalaria, de que, segundo a autora, Bertrand Du Guesclin seria o modelo por excelência.

${ }^{49} \mathrm{Na}$ historiografia há diferentes abordagens do personagem Du Guesclin: não mais que um mercenário que se servia de táticas de combate nada além de brutais; usurpador por ter se beneficiado, inclusive financeiramente, ao apoiar o bastardo Henrique Trastâmara contra Pedro, o Cruel; traidor da Bretanha profunda ao permanecer ao lado da monarquia francesa contra Montfort que, após a morte de Carlos de Blois, assumiu o ducado, etc., visões que são de qualquer maneira interessantes quando a tradição historiográfica francesa do século XIX se empenhou em colocar Du Guesclin como o herói nacional modelo.

${ }^{50}$ FEBVRE, Lucien. Combats pour l'histoire. Paris: Lib. Armand Colin, 1992, p. 428.

${ }^{51}$ FERNANDES, "Usurpações, casamentos régios ...", p. 15.
} 
que Du Guesclin] não tenha incarnado o ideal de cavaleiro perfeito. $^{52}$

De qualquer maneira, nem Deschamps e nem tampouco Christine de Pizan fizeram referência às estratégias de $\mathrm{Du}$ Guesclin como algo fora dos padrões cavaleirescos, embora, saibamos que sua aclamada estratégia para operações militares dê abertura para conjecturarmos sobre certas novidades que o militar bretão pode ter introduzido nas artes da guerra ao liderar seus pelotões.

Além de vaillant connétable, a designação de Du Guesclin como o décimo preux é igualmente instigante. Em Deschamps ela não aparece de maneira explícita, mas o atributo de preux é conferido a Du Guesclin muitas vezes nos textos do poeta champenois. A lista canônica dos nove preux surgiu em uma canção de gesta do início do século XIV, os Voeux du paon, de Jacques de Longuyon, em que são elencados os nomes de personagens célebres reunidos da seguinte forma, três heróis da Antiguidade, Heitor, Alexandre, o Grande e Júlio César; três heróis do Antigo Testamento, Davi, Josué e Judas Macabeus, e três heróis cristãos da Idade Média, o rei Artur, Carlos Magno e o cruzado Godofredo de Bulhão. O que Deschamps fez foi, no canto real 362 por exemplo, composto ainda quando o condestável vivia, por volta de 1373, citar Du Guesclin logo após a lista dos preux e afirmar (v. 8-10):

Pour faire bien, pris, honeur et vaillance Seroit entr'eulx bien amez et venuz B. du Guesclin, connestable de France.
Por fazer bem, valor, honra e valentia Será entre eles bem amado e vindo B. Du Guesclin, condestável da França.

Apesar de Deschamps não o declarar como o décimo ${ }^{53}$ dentre os valentes heróis, não há como não atribuir ao poeta o papel de importante propagador de Du Guesclin como um modelo de cavaleiro a serviço da glória da coroa francesa.

Il doit amer son seigneur droiturier, Et dessus touz garder sa seignourie, Largesse avoir, estre vray justicier, Des prodommes suir la compaignie, Leurs diz oir et aprandre,

Et des vaillants les prouesses comprandre, Afin qu'il puist les grans faiz achever Comme jadis fist le roy Alixandre : Ainsi se doit chevalier gouverner. Balada 1165
Ele deve amar seu senhor legítimo, E sobre tudo guardar seu senhorio, Generosidade ter, ser verdadeiro justiceiro, Bons homens seguir a companhia, Seus ditos ouvir $e$ aprender, E dos valentes as proezas apreender, A fim de que possa os grandes feitos completar Como outrora fez o rei Alexandre: Assim deve o cavaleiro se governar. ${ }^{54}$

\footnotetext{
${ }^{52}$ GUENÉE, Bernard. Du Guesclin et Froissart. La fabrication de la renommée. Paris: Tallandier, 2008, p. 89,90 e 92 .

${ }^{53}$ Ficaria a cargo do trovador da região da Picardia, Cuvelier, a menção de Du Guesclin como o dixième preux, em sua Canção de Bertrand Du Guesclin, canção de gesta tardia composta em honra ao condestável entre os anos de 1380 e 1385. Algumas das baladas que são atribuídas a Deschamps, como a peça XXIX, por exemplo, referem diretamente o cavaleiro como um dos nove valentes (Cf. Euvres Complètes, tomo X, p. XXXVI-XXXVII, versos 17 e 22).

${ }^{54}$ Para esta citação e a anterior, adotamos um trabalho de tradução semântica.
} 
Neste ponto, cabe, sem dúvida, um pequeno parêntesis sobre as relações pessoais de vassalagem ainda em vigor no final do século XIV no Ocidente latino. Assim como a fidelidade de Du Guesclin era dirigida à pessoa do rei Carlos V, nos seus anos de connétablie, Deschamps, por sua vez, também ilustrava essa realidade ao ser fiel às preferências de seu senhor, o duque Luís de Orléans, cujo padrinho de batismo foi ninguém menos que Bertrand Du Guesclin, em $1372^{55}$. Sabe-se além disso que o duque fez erigir uma estátua de Du Guesclin e a colocou em uma grande sala de seu castelo em Coucy, adquirido em 1400, em que já figuravam os outros nove preux, estátuas feitas sob o antigo proprietário, Enguerrand $\mathrm{VII}^{56}$, o que remete a uma longa tradição de exaltação dos valores estimados pela cavalaria.

A propósito, a cavalaria, naqueles fins de século, estava também em transformação, como já dissemos, e servia de tema para propostas reformadoras da política, referida muitas vezes como modelo a ser seguido, juntamente com os valores religiosos. A exemplo disso, a obra do cavaleiro francês Philippe de Mézières, o Songe du Vieux Pèlerin, de 1389, oferecida a Carlos VI. Trata-se de um texto alegórico que serviu ao jovem rei de espelho de príncipe. Philippe de Mezières aconselha ao monarca manter os valores cavaleirescos tais como a perfeição individual ${ }^{57}$, a obediência e a prontidão, o que derivou logo em sugestóes para que o rei fizesse de sua cavalaria um corpo armado a serviço do reino ${ }^{58}$. A nova cavalaria proposta por Philippe de Mézières serviria a corrigir os cavaleiros da cristandade que ora mostravam-se antes servos da glória pessoal que do próprio Cristo.

\section{Considerações finais}

Eustache Deschamps foi um homem de saber na França do final do século XIV, podemos até mesmo concordar que ele e seus pares

reconheceram no saber um poder essencialmente integrador $e$ modernizador, que eles tenham visto no mesmo saber o cimento da coesão social e política e que eles não tenham jamais sido tão felizes como no momento em que tiveram por interlocutor um rei "sábio" partilhando suas convicções e

55 O texto de autor anônimo da Chronique des Quatre Premiers Valois apresenta o segundo filho de Carlos V, o futuro Luís de Orléans, no seu nascimento em março de 1372 dizendo que ele foi "levado às fontes batismais pelo conde de Estampes, pelo senhor Bertrand Du Guesclin, condestável da França, e pelo senhor Olivier de Clisson. E como a criança se deixou batizar, o dito senhor Bertrand lhe deu uma espada que colocou em sua mão dizendo que Deus e São Jorge o fizessem bom cavaleiro" (Chronique des Quatre Premiers Valois. Paris: Société de l'Histoire de France, 1861, p. 226).

56 LUCE, Siméon. Du Guesclin, dixième Preux, Comptes rendus des séances de l'Académie des Inscriptions et Belles-Lettres, 32e année, N. 5, 1888, pp. 408-409. Disponível em www.persee.fr. Acesso em: $19 \mathrm{dez} .2014$.

${ }^{57}$ Do latim, a summa perfectio. Ver HUIZINGA, Johan. O outono da Idade Média. São Paulo: Cosac Naif, 2010, p. 130-131.

58 PHILIPPE DE MEZIERES. Songe du Vieux Pèlerin. Traduit de l'ancien français par Joël Blanchard. Paris: Pocket « Agora », 2008, p. 877-882. 
Ora, os ouvintes ou os leitores de uma obra tal como a de Deschamps jamais questionariam se o que o poeta lhes oferecia era verdade ou não; a verdade estava posta na obra e por ela mesma, e ainda mais porque, no caso dos versos em homenagem a Du Guesclin, se tratava de um personagem próximo a muitos deles e além disso o condestável trazia consigo um valor muito caro àquela monarquia, o serviço à coroa. Memória e reconhecimento coletivos eram prementes; segundo Paul Ricoeur, são esses dois elementos de comparação que podem evidenciar até que ponto uma obra ambicionou ou não "compensar por sua cadeia de mediações a carência do momento de reconhecimento que faz com que a memória permaneça a matriz da história" ${ }^{60}$. Dessa forma, concordamos com o historiador Jaume Aurell, quando ele se refere às obras medievais sempre levando em conta seu contexto de produção:

Por esto, siempre he defendido que la interpretación de los textos histórico-medievales es fruto no solo de su consideración como un "artefacto literario" o como las "narraciones históricas" que más evidentemente son, sino también como una fuente privilegiada de convergencia entre el texto y el contexto, entre el contenido y la forma. Se descubre así una función pasiva y una función activa de los textos históricos, según estos sean considerados como espejos o como generadores de realidades sociales. [Grifos do autor].$^{61}$

Aliás, a importância da poesia na conservação dessa memória e na geração de realidades sociais pode ser averiguada em muitos exemplos, haja vista o riquíssimo conteúdo conservado nos cancioneiros medievais. Isso também foi o assunto explorado pelo pesquisador Hermenegildo Bastos em seu artigo "Ficcional e Verídica (Notas sobre a historicidade da poesia)", em que coloca que "a poesia evoca e preserva os fenômenos históricos decisivos. Por fazê-lo converte-se em memória da humanidade [...]. Uma memória de que a humanidade não pode se desfazer" ${ }^{\prime \prime 2}$, o que nos faz referir Homero.

\footnotetext{
${ }^{59}$ VERGER, Homens e saber..., p. 206.

${ }^{60}$ RICOEUR, Paul. «L'écriture de l'histoire et la représentation du passé ». Annales. Histoire, Sciences Sociales. $55^{e}$ année, $\mathrm{n}^{\circ} 4,2000$, p. 745-747. Disponível em: http:// www.persee.fr/doc/ahess_03952649_2000_num_55_4_279877. Acesso em 14 fev. 2017.

${ }^{61}$ AURELL, Jaume. La historiografía medieval, entre la historia y la literatura. València: PUV - Universitat de València, 2016, s/p. Disponível em: https://books.google.com.br/books/about/ La historiograf\%C3\%ADa medieval.html. Acesso em: 21 maio de 2018.

${ }^{62}$ BĀSTOS, Hermenegildo. "Ficcional e Verídica (Notas sobre a historicidade da poesia)". Revista Letras, Curitiba, UFPR, $\mathrm{n}^{\circ}$ 94, p. 36-50, jun./dez. 2016. Disponivel em: http://revistas.ufpr.br/letras/article/view/46090. Acesso em: 14 fev. 2017.
} 
Cabe ao historiador da cultura "aproximar pessoas"63 e ao analisar os textos líricos e de expressão subjetiva do medievo francês, intentamos mostrar como é possível, na nossa contemporaneidade, tecer consideraçóes sobre aquilo que ocupava o tempo dos homens e mulheres de letras atuantes naquele período. Foi possível perceber, por exemplo, que Eustache Deschamps não era indiferente ao que sucedia a seu redor, nem ao que poderia ser interessante a seus mecenas. Por outro lado, Deschamps não deixou de criticar a ação dos poderosos nas armas e nos tronos, além, é claro, de ser um pensador que ruminava sobre sua própria prática poética.

Como vimos, o cultivo do entorno dos homens de saber e dos homens de armas foi fundamental para que os testemunhos deles chegassem até nós. Pena e espada não bastariam para que esses homens fossem constantemente revisitados pela História? A proximidade com os poderosos sem dúvida lhes conferiu legitimidade para atuar como atuaram, trabalhando e bem para seus renomes, dignos de memória. São todos os vestígios que restaram de suas existências, repletas de ações ou palavras, referendados ou não pelo poder dos senhores, que permitem ao trabalho $e$ à arte do historiador reconfigurar suas vidas.

\section{$\operatorname{son} 2$}

${ }^{63}$ BURKE, Peter. O que é história cultural? Tradução Sergio Goes de Paula. 2.ed.rev. e ampl. Rio de Janeiro: Zahar, 2008, p. 180. 


\section{RESUMO}

Este artigo pretende demonstrar de que forma a poesia lírica de Eustache Deschamps (ca. 13431406), poeta francês bastante profícuo da Baixa Idade Média, pode fornecer elementos que enriquecem $e$ ampliam o conhecimento sobre a cultura $e$ a sociedade desse período. Acreditamos que cabe ao historiador que convoca textos literários a compor suas fontes, ter consciência de que tais documentos podem fornecer indícios de como foi a sociedade de corte na França do final do século XIV, por exemplo, e de como se dava sua relação com homens e mulheres de letras, portanto, cabe ao pesquisador fazer as perguntas corretas segundo sua hipótese de trabalho. Ao salientarmos alguns detalhes da composição de Eustache Deschamps sobre o cavaleiro bretão Bertrand Du Guesclin, intentamos mostrar que o poeta champenois não era indiferente ao que sucedia a seu redor, notadamente os males causados pelos conflitos da Guerra dos Cem Anos (13371453), bem como estava atento aos interesses militares de seus senhores no que se referia à cavalaria, sem deixar de tecer suas críticas ao comportamento dos combatentes, da aristocracia e do próprio rei.

Palavras-chave: Baixa Idade Média; Eustache Deschamps; Bertrand Du Guesclin.

\section{ABSTRACT}

The purpose of this article is to demonstrate the way in which the lyric poetry of Eustache Deschamps (ca. 1343-1406), a highly prolific French poet of the Late Middle Ages, can provide elements that enrich and broaden the understanding of the culture and society of this period. We believe that it is the historian's role to summon literary texts to compose his/her sources to be aware that such documents can provide indications of how the court society in France at the end of the XIV century, for instance, and of the relationships between men and women of letters. Thus, it is his/her responsibility to ask the correct questions according to the working hypothesis. By underscoring some elements of the composition of Eustache Deschamps on the Breton knight Bertrand Du Guesclin, we seek to demonstrate that the champenois poet was not unaware of what took place in his milieu, particularly the evils caused by the conflicts of the Hundred Years' War (1337-1453), as well as the military interests of his masters with respect to the cavalry, while also providing criticism of the behavior of the combatants, of the aristocracy, as well as the king himself.

Keywords: Late Middle Ages; Eustache Deschamps; Bertrand Du Guesclin.

Artigo recebido em 22 mar. 2017.

Aprovado em 17 mai. 2018. 